\title{
Research
}

\section{Paraphrasing in Academic Writing: a Case Study of Vietnamese Learners of English}

\author{
Chi Do Na \\ An Giang University, Vietnam \\ ORCID ID 0000-0003-1292-9397 \\ Nguyen Xuan Nhat Chi Mai \\ Hue University, College of Foreign Languages, Vietnam \\ ORCID ID 0000-0003-1276-8589
}

\begin{abstract}
Paraphrasing is an important skill in academic writing - it is a cognitive skill that requires higher order thinking and high proficiency inss both reading and writing. This research explored the paraphrasing ability of EFL learners at a tertiary institution in Vietnam and examined the challenges they face when paraphrasing. Data were collected from ten second-year English major students through (i) paraphrasing a given text and (ii) individual interviews. The findings revealed that participants frequently paraphrased using synonyms, but rarely changed syntactic structures. The interviews showed that the learners encountered several language-related difficulties when attempting to paraphrase, such as inadequate understanding of the source text and the lack of vocabulary to use when paraphrasing. This paper provides insights into EFL learners' paraphrasing abilities and suggests some implications as to what EFL teachers should focus on to help less experienced student writers improve their paraphrasing skills.
\end{abstract}

Keywords: paraphrasing, academic writing, EFL, Vietnamese learners

In English courses at Vietnamese universities and colleges, writing plays an important role as a majority of course assignments are done in the form of essays and written reports. This frequent use of text-based assessments leads to a concern among language educators, namely that their learners might resort to plagiarism, or copying source texts without proper citation. One technique to prevent plagiarism and improve students' academic writing skills is paraphrasing (Gardner, 1999).

However, paraphrasing in a second or foreign language is generally considered more difficult than in a mother tongue (Keck, 2006, 2014), especially for language learners who are

Language Education in Asia, 2017, 8(1), 9-25. http://dx.doi.org/10.5746/LEiA/17/V8/I1/A02/Na_Mai 
inexperienced in the academic world. Studies conducted with L2 English learners' paraphrasing practices have reported on their failure to paraphrase effectively due to two main reasons: the lack of awareness of the importance of paraphrasing and techniques for doing it (Hirvela \& Du, 2013; Khairunnisa, Sutapa, \& Surmiyati, 2014), and insufficient language proficiency (Keck, 2006, 2014; Liao \& Tseng, 2010; Milicevic \& Tsedryk, 2011; Shi, 2004). In addition, several scholars (e.g., Chien, 2014; Keck, 2014; Shi, 2004) have discussed L2 learners' paraphrasing problems in terms of their cultural attitudes toward texts. Specifically, in some cultures knowledge is seen as a property of the society; everyone has the right to use that knowledge for their own purposes, so copying chunks from original texts is considered preferable (Chien, 2014).

These previous studies, however, have focused on identifying L2 learners' linguistic difficulties when attempting to paraphrase and paid less attention to learners' voices and perspectives about paraphrasing. The present study therefore was conducted to not only investigate the paraphrasing ability of Vietnamese college-level EFL learners, but also explore the challenges they face when attempting to paraphrase in academic writing. The paper starts by looking at previous studies on the issue of paraphrasing, followed by descriptions of the methodology used to obtain data for the research. It then presents the research findings and discussion in relation to relevant research on L2 learners' paraphrasing skills. The paper concludes with pedagogical implications for helping less experienced student writers improve their paraphrasing ability.

\section{Literature Review}

\section{Paraphrasing and Its Techniques}

Most researchers, when clarifying the meaning of paraphrasing, focus on changes in word use and syntactic structures and the similarity of meaning between the original and paraphrased texts. For example, Richards and Schmidt (2010) defined "paraphrase" as "an expression of the meaning of a word or phrase using other words or phrases, often in an attempt to make the meaning easier to understand" (p. 420). In addition, Bailey (2006) put forward the idea that paraphrasing involves changing a text while still retaining its meaning. As these definitions show, a paraphrased text contains different lexical and syntactic items from the source, but retains the meaning. One further point is that paraphrasing does not shorten the length of text, which distinguishes paraphrasing from summarizing (Hirvela \& Du, 2013).

In order to successfully paraphrase, L2 learners need to utilize complex cognitive and linguistic skills. First, they have to understand the meaning of the text properly, which activates their reading ability (Wette, 2010). The next step is to select important points of the source text so as to transform and integrate them into their writing in a meaningful and accurate way (Shi, 2004). This transformation can be done by using appropriate lexical items to replace those in the original text. Specifically, Bailey (2006) suggested using synonyms (e.g., studies in place of research), changing word class (e.g., in the mountains for mountainous regions), changing word order (e.g., the collapse of Egyptian society began for Ancient Egypt collapsed), or a combination of all of the above-mentioned techniques. Additionally, Rogers (2007) recommended changing sentence structures (e.g., from active to passive, direct speech to indirect speech), or using other structures appropriately and correctly while paraphrasing. 
These two techniques have also been reported to be frequently used by L2 English learners in their attempts to paraphrase (see Keck, 2006, 2014).

\section{The Importance of Paraphrasing}

Paraphrasing is an important skill in second language academic writing. First, it prevents learners from plagiarizing as experienced L2 writers who are familiar with paraphrasing techniques have been found to rely less on source texts than their novice peers (see Keck, 2014). Second, paraphrasing can also show learners' understanding of the source text (Keck, 206; Wette, 2010) and demonstrates how well they can read and write in their second language. It is therefore a beneficial indicator for $L 2$ teachers to gain insight into their learners' reading and writing ability (Li \& Casanave, 2012). Moreover, according to Hirvela and Du (2013), paraphrasing is not only a useful linguistic tool for L2 learners to manipulate the language of existing literature to integrate into their writing (knowledge telling), but it is also a meaning-making process that contributes to developing the content of their writing (knowledge transformation). This means that good paraphrases can enhance the persuasiveness and thus the rhetorical power of a piece of writing.

\section{The Reality of Paraphrasing in Second Language Education}

Numerous studies have reported on L2 learners' unsuccessful attempts at paraphrasing. In particular, Keck (2006) compared paraphrasing strategies used by L1 and L2 English writers at a US university, and found that more L2 writers' papers could be categorized as "Near Copies", while more L1 writers' paraphrased texts fell under the categories of "Moderate revision" and "Substantial revision". These types of paraphrase, as explained by Keck, are based on the calculation of the number of word uses that are similar between the source and the paraphrased text. Similarly, L2 learners in other studies (e.g., Khairunnisa et al 2014; Liao \& Tseng, 2010; Milicevic \& Tsedryk, 2011; Pecorari, 2003; Shi, 2004) were reported to copy large chunks of words or phrases from source texts without proper references.

Most of the above-cited studies examined problems with L2 learners' paraphrasing based entirely on analyzing their written work. While this provides useful evidence about learners' paraphrasing abilities, it does not shed light on their perspectives and thought processes as learners paraphrased. The smaller number of studies that did this through surveys and interviews with student writers were able to provide valuable insights into students' perception of paraphrasing as well as reveal difficulties that they faced while paraphrasing. Hirvela and Du (2013) is one of the few studies that qualitatively examined paraphrasing from L2 learners' perspectives and found that their participants were well aware of the importance of paraphrasing. Nevertheless, they considered paraphrasing more as linguistic manipulation to prevent them from plagiarism, rather than a significant tool for language learning and knowledge transforming. These scholars then argue against limiting the teaching of paraphrasing to mainly linguistic-oriented techniques, as this fails to enable L2 writers to see the rhetorical power of paraphrasing in enriching the content of their written work.

In terms of difficulty in paraphrasing, Khairunnisa et al (2014) reported that the reasons why Thai university learners in their study were not able to paraphrase well were their unawareness of the method of paraphrasing and their lack of understanding of what constitutes good 
paraphrases. Other researchers, however, have argued that even when L2 learners are highly aware of different paraphrasing techniques, they might fail to produce good paraphrased texts in practice due to their limited language proficiency. For example, Liao and Tseng (2010) found that their Chinese participants did not appropriately paraphrase despite having been taught in their English classes about how to use synonymous vocabulary to reconstruct source texts. This study revealed that this was due to learners' lack of vocabulary to change the words in the original texts. This finding resonates with Milicevic and Tsedryk (2011) and Hirvela and Du (2013), in which L2 earners admitted their difficulties in utilizing lexical resources for paraphrasing.

Most existing studies have focused on identifying L2 learners' linguistic difficulties when attempting to paraphrase. However, those studies have paid less attention to learners' voices and perspectives about paraphrasing (Hirvela \& Du, 2013). Also, despite a growing body of research on the paraphrasing ability of $\mathrm{L} 2$ English learners, little research of this kind has been conducted with Vietnamese learners in the context of English teaching and learning in Vietnam. Against this background, this research was conducted to explore Vietnamese EFL learners' paraphrasing ability and to uncover both linguistic and non-linguistic factors (e.g., awareness of paraphrasing) that hinder the effectiveness of their paraphrasing.

\section{Research Questions}

\section{Methodology}

This study aims to address the following questions:

1) How do Vietnamese EFL learners paraphrase?

2) What are their perceptions of paraphrasing? Specifically,

2.1. To what extent are they aware of the importance of paraphrasing?

2.2. What are their difficulties in paraphrasing?

\section{Context and Participants}

The participants were ten English major learners (five males and five females) in their second year of study at a public university in Vietnam. All participants speak Vietnamese as their first language. Prior to taking part in the study, they had had eight years of English instruction at school level and one year of intensive English training at university. At schools these participants had two to three hours of English instruction per week and their English classes were focused on grammar and vocabulary acquisition. As English major learners at university, they had intensive practice in all the four skills, including writing. The learners' English proficiency was estimated to be at B1 level according to the Common European Framework of Reference (CEFR) as they had passed final tests designed in accordance with CEFR at B1 level at the end of their first year of study.

These participants were randomly selected from a class of 24 learners. At the time the research was conducted, they were in the process of learning to write academic essays and had been taught about the importance of paraphrasing. They had also had the opportunity to practice paraphrasing in their academic writing class. 


\section{Data Collection Instruments}

Paraphrasing practice. The participants were required to paraphrase a text of 288 words provided by the researchers (see Appendix A). The participants were first shown the text and asked to read through it to gain an understanding. Then, they were required to rewrite the ideas of the original text. The text was about homework and its pressure on young learners, which is one of the common topics in education. Its level of difficulty was measured using the Vocabulary Profile (VP) tool available at www.lextutor.ca (Savier, 2004). The VP conducts word frequency analyses based on Laufer and Nation's (1995) Lexical Frequency Profile (LFP) index, which represents the proportion of frequent versus non-frequent vocabulary in a text. According to this measurement, $80 \%$ of the words in the original text used for this paraphrasing practice belong to the most frequent 1000 word families in English, 4.4\% to the second 1000 words, 4.4\% in the Academic Word List (see Coxhead, 2000), and only $11.2 \%$ do not belong to any of these lists (less frequent words). This indicated that the language of the text was aligned to the participants' reading proficiency level.

Interviews. Semi-structured interviews were carried out with all ten participants. Each interview lasted between 15 to 20 minutes and focused on eliciting the challenges participants experienced while doing the paraphrasing exercise, as well as their reasons for using particular paraphrasing techniques (see Appendix B). The interviews were conducted a day after the paraphrasing activity to allow the researchers time to evaluate the participants' paraphrased texts and have an idea of their paraphrasing abilities before interviewing them. Vietnamese was used in all interviews as it was the shared language between the participants and the researchers.

\section{Data Analysis}

After the participants finished their paraphrasing practice, their paragraphs with paraphrased parts were collected and compared with the original text. When comparing the texts, the researchers paid attention to similarities and differences in word use, structures, and meaning of the two texts. Based on this, participants' paraphrased texts were categorised as either "successfully paraphrased" or "unsuccessfully paraphrased". The former contained substantial modification in word use and structures, while still retaining the meaning of the original text; and the latter either copied large chunks from the original text with little or no modification, or attempted to change word use and structures but the original meaning was either changed or obscured. Additionally, paraphrasing techniques used by the participants were identified following Bailey's (2006) and Rogers' (2007) categorisation of techniques for paraphrasing (see Literature Review section for descriptions of these techniques).

The ten interviews were transcribed and coded by the first author according to three phases of qualitative content analysis (Braun \& Clarke, 2006; Dörnyei, 2007). In the first phase, relevant data segments were located. Specifically, the whole data set was first read through and segments containing the students' explanations of their paraphrasing techniques and the difficulties they faced while paraphrasing were highlighted. Next was generating initial codes. All highlighted segments were read again and initial codes were given to the segments based on keywords and phrases in the segments that directly referred to difficulties in paraphrasing. Finally, existing codes were examined and grouped into potential themes and clear names 
were then generated for each theme (see Appendix $C$ for a coding example). The coding process was done with the Vietnamese transcription. Interview excerpts that were included in this report were translated into English by the first author and cross-checked by the second author. To ensure the reliability of the coding, the second author coded 30 percent of the interview data and confirmed the individual codes and emerging themes.

While findings from the paraphrasing practice demonstrated learners' paraphrasing abilities, hence addressing the first research questions, the interview findings revealed participants' strategies and preferences when paraphrasing, as well as their perception of paraphrasing (research question 2).

\section{Findings}

\section{Participants' Paraphrasing Abilities}

The first research question sought to examine Vietnamese EFL learners' paraphrasing ability. Analyses of the ten participants' paraphrased texts revealed that student performance differed markedly, and could be categorized into two groups. The first group contained four participants who were able to paraphrase the text well. The other group were those who had problems in their paraphrasing and did not make successful changes in their texts.

For the group who were able to paraphrase well, synonyms were employed the most in their paraphrased texts. Specifically, each piece of paraphrased work contained from 20 to 25 words and phrases that were replaced by their synonyms. Table 1 summarizes some common replaced words and phrases.

\section{Table 1}

Examples of Synonyms in Successfully Paraphrased Texts

\begin{tabular}{|l|l|}
\multicolumn{1}{|c|}{ Original text } & \multicolumn{1}{c|}{ Paraphrased texts } \\
\hline Today & Recent days/Nowadays \\
\hline Amount & Too much/A lot of \\
\hline Keeps them from & Prevent them from \\
\hline Having fun & Entertain/Relax \\
\hline Protesting & Objecting/Refusing \\
\hline Give up & Forgot \\
\hline Loaded down & Tired of/Tired to \\
\hline Responded favorably & Supported \\
\hline Refused & Rejected/Don't accept \\
\hline
\end{tabular}

Another frequently used technique for paraphrasing by this group was changing word forms (e.g., nouns to verbs). From 5 to 7 instances of word form changes were found in each paraphrased text. Table 2 contains some examples of word transformation. 


\section{Table 2}

Examples of Word Transformation in Successfully Paraphrased Texts

\begin{tabular}{|l|l|}
\multicolumn{1}{|c|}{ Original text } & \multicolumn{1}{c|}{ Paraphrased text } \\
\hline [homework they] Get & Getting [homework] \\
\hline [keeps them from] Playing & [make them unable to] Play \\
\hline [make] Boring [kids] & [make them] Bored \\
\hline [Children] Need & [Children are in] Need of \\
\hline [need] To play & [in need of] Playing \\
\hline Pressure [for children] & [children are] pressured \\
\hline
\end{tabular}

Noticeably, although using different structures had been taught as one of the paraphrasing techniques, the participants did not apply it in their writing as frequently. To illustrate, only 5 to 7 instances were related to syntactic modification. Table 3 shows some examples of syntactic transformation.

Table 3

Examples of Syntactic Transformation in Successfully Paraphrased Texts

\begin{tabular}{|l|l|}
\hline \multicolumn{1}{|c|}{ Original text } & \multicolumn{1}{c|}{ Paraphrased texts } \\
\hline A recent study ...reports that.... & $\begin{array}{l}- \text { In a recent study ..., it is reported that... } \\
- \text { According to a recent study ..., we can } \\
\text { see that... }\end{array}$ \\
\hline The question is whether & - He wonders whether/He said that \\
\hline $\begin{array}{l}\text { Pressure for students to perform well on } \\
\text { standardized tests has led schools to pile } \\
\text { on at-home assignments }\end{array}$ & $\begin{array}{l}- \text { Kids must be at home to finish their } \\
\text { exercises and can't go out }\end{array}$ \\
\hline
\end{tabular}

Meanwhile, the second group of learners who did not paraphrase well either copied the original sentences or changed some words which obscured the meaning of the text. An example of this is shown below (replaced words that obscure or change the meaning of the original text are underlined).

Now, kids find out that the amount of homework they get keeps them from playing sports, taking music lessons or just having fun after school. Recently, a research by the University of Michigan reports that more than past 16 years, the amount of time the average 3 to 11-year-old kid spends on homework has developed by 50 percent. More and more parents are protesting against so much homework. (Participant 5)

As seen in the paraphrased excerpt above, the participant changed only a few words in the original text. She also misunderstood the meaning of the phrase "over the past 16 years" in the source text, and replaced "over" with "more than", which completely changed the original meaning.

Another example of inappropriate paraphrasing from this group is due to irrelevant word use and copied vocabulary from the source text: 
Nowadays, children find out the amount of homework they mix them with sports, music or just daily game. A recent research by the University of Michigan reports that more than past 16 years ago, the amount of time the average 3 to 11 -year-old kid spends on homework has developed 50 percent. (Participant 6)

The interviews shed light on the participants' strategies and preferences when paraphrasing. The first group of participants who were able to paraphrase were well aware of paraphrasing strategies. All four participants indicated that they used synonyms the most in paraphrasing because they found it simpler than altering sentence structures. For example, Participant 1 elaborated, "I think it is easier for me to change the words because if I have to change the whole sentence, I am not sure that I will use correct structures".

These participants also explained their preference for using different word forms in paraphrasing. The most cited reason (by all four participants) was because this was an easier technique than having to think of synonyms. Participant 1 said that "I feel that it is easy to use different word forms because I do not need to think much about what words to use". Similarly, Participant 4 stated, "I think that changing word form is a safe way because the meaning of the sentence does not change".

Finally, using a completely new structure was thought to be useful but not preferred by the participants. Three of them reported that they were not confident that the original meaning would be retained if they changed the syntactic structure of the text. Participant 2's response illustrates this point:

I was told by my teacher that it is very good to use a different structure to make impressions to the examiners, but sometimes I do not know what structures to use. I am afraid that I will not use correct structures or will change the meaning of the sentence.

\section{Participants' Perceptions of Paraphrasing}

The second research question addressed participants' perceptions of paraphrasing, particularly their awareness of and difficulties in paraphrasing.

Awareness of paraphrasing in academic writing. All interviewed participants indicated that they had been aware of the term paraphrasing and were given opportunities to practice paraphrasing in the form of sentences and paragraphs in their writing courses. In addition, seven participants claimed to be highly aware of the importance of paraphrasing in academic writing. They either considered paraphrasing as a useful technique to help them avoid copying ideas from original texts (participants 1, 2, 4, 5) or a demonstration of their language ability (participants 6, 7, and 10).

Difficulties in paraphrasing. The common difficulty that the participants shared was languagerelated problems. The group who paraphrased well reported that they could understand the given text well, but lacked vocabulary to use for paraphrasing. Therefore, occasionally they 
had to use the same words as those in the original text. Table 4 contains examples of participants' reusing words from the original text.

\section{Table 4}

Examples of Unchanged Language Patterns in Paraphrased Texts

\begin{tabular}{|l|l|}
\hline \multicolumn{1}{|c|}{ Original text } & \multicolumn{1}{c|}{ Paraphrased text } \\
\hline $\begin{array}{l}\text { A recent study by the University of Michigan reports } \\
\text { that over the past 16 years, the amount of time the } \\
\begin{array}{l}\text { average 3 to 11-yearold kid spends on homework has } \\
\text { increased by 50 percent. }\end{array}\end{array}$ & $\begin{array}{l}\text { According to a recent study of University of Michigan, } \\
\ldots \text { the average time a child from 3 to 19 years old } \\
\text { spends on doing homework is increasing by 50 } \\
\text { percent over the past 16 years. (Participant 3) }\end{array}$ \\
\hline $\begin{array}{l}\text { Research confirms that doing homework is better } \\
\text { than not doing homework. }\end{array}$ & $\begin{array}{l}\text { Doing homework was better than not doing } \\
\text { homework. (Participant 4) }\end{array}$ \\
\hline
\end{tabular}

On the other hand, the group who were not able to paraphrase well attributed their unsuccessful paraphrasing attempts to their difficulties in understanding the given text. They thought paraphrasing was problematic or even impossible because they were not able to comprehend the original text or interpret it appropriately. Participant 7 commented: "I found the text difficult to understand so I am not sure that I had used correct words to replace those in the original texts".

Additionally, even in instances where they were able to comprehend the original message, another difficulty that this group of participants had was also related to limited lexical and syntactic knowledge. Six participants who were not able to paraphrase well recognized that they needed to use almost the same words since they had no other words to replace them. For example, Participant 5 stated, "I know that I should change the words that they use in the text but because I do not know other words, I did not change." Notably, eight participants admitted they were not confident that the words they were going to use could retain the meaning of the text; therefore, the best way for them was to keep the words in the text as a more secure solution. Similarly, these participants commented that even when they could understand the text, they did not always change syntactic structures unless they were sure of the accuracy of those changes. As Participant 6 remarked, "I am afraid that I will make mistakes if I try to change words or structures. It is better to copy than to write wrong sentences".

\section{Discussion and Implications}

Findings of the present study provide insights into Vietnamese EFL learners' paraphrasing ability. In this section, these findings will be discussed in light of previous research on L2 learners' paraphrasing skills. We will also suggest pedagogical implications for teachers working to improve L2 learners' paraphrasing abilities.

\section{Learners' Perceptions of Paraphrasing}

Participants of the current research showed an awareness of the importance of paraphrasing. They considered paraphrasing to be an important skill to use when writing academically as it helped them to avoid plagiarism and thus obtain better study results. However, like the participants of Hirvela and Du (2013), their attitudes toward paraphrasing seemed to be mainly 
at the linguistic level. The participants did not see paraphrasing as a tool for them to engage meaningfully with authors of source texts and assist them in better conveying their own thoughts or opinions on a writing topic. This attitude might have influenced their selection of techniques to use when paraphrasing, which will be discussed in the section that follows.

\section{Learners' Preferences toward Paraphrasing Techniques}

In the present study, the group of participants who were able to paraphrase successfully were seen to make more changes in vocabulary than in sentence structures. Particularly, using synonyms was a popular technique among the participants. these results resonate with previous research on L2 learners' paraphrasing practice (see Keck, 2006, 2014; Khairunnisa et al, 2014; Liao \& Tseng, 2010), which also found that L2 learners often relied substantially on their lexical resources when attempting to paraphrase. Importantly, the current study also uncovered that the participants preferred using synonyms than changing sentence structures because they were afraid that their transformation might change its meaning. One possible explanation for this could be traced back to these learners' attitude toward academic texts. In fact, research has shown that inexperienced L2 writers often felt inferior to authors of source texts and therefore did not feel confident enough to engage with them at a deeper level (Hirvela \& Du, 2013; Macbeth, 2010). another reason could be because in Vietnamese writing, direct quotations, or statements from well-known figures or authors (Phan, 2006), are more frequently employed and often considered more effective in strengthening an author's argument than paraphrasing. Since the use of direct quotes requires no changes of lexis or syntactic structures, this might explain why Vietnamese learners of English might not think it is necessary to change the source text dramatically by altering its words or sentence structures.

\section{The Relationship between L2 Learners' Language Proficiency and Their Paraphrasing Abilities}

For the group of participants who did not do well in the paraphrasing exercise, their most common problem was limited ability to comprehend the text. Consequently, most of their paraphrased works were still very similar to the original text in terms of word use and sentence structures. There were even instances in which participants misunderstood the given text and used expressions that changed or obscured meaning in their paraphrased texts. This finding confirms the close link between L2 learners' reading competence and their paraphrasing ability, as has been pointed out by existing research (Keck, 2006; Li \& Casanave, 2012; Shi, 2004; Wette, 2010). On the other hand, other research (e.g., Keck, 2014) has shown that learners' use of copying or minimal revision of source texts cannot always be associated with their limited paraphrasing skills or language proficiency. L2 writers in Keck (2014) were found to mainly use paraphrases when doing a summary task, and only copy in instances where they thought it was important to retain the main points of the source text. This difference in findings could be because Keck's study made use of summary writing in which learners were required to selectively decide what to include in a much shorter summary paragraph than the source text, whereas in the present study participants were straightforwardly asked to paraphrase all of the source text, not summarise it. Another difference is that all participants of the present study who did not properly paraphrase the source text explicitly acknowledged that their limited language proficiency was a hindrance to their paraphrasing practice. This supports the 
argument that L2 learners' language proficiency might negatively influence their paraphrasing abilities.

Another language-related difficulty commonly cited by participants of the present study is the lack of vocabulary to use when paraphrasing. They stated that it was not easy for them to find other words to restate the original ideas. This finding resonates with other studies which reported that many L2 learners were faced with language-related problems when attempting to paraphrase (e.g, Khairunnisa et al., 2014; Liao \& Tseng, 2010; Milicevic \& Tsedryk, 2011).

\section{Implications for Teaching}

It has been reported that participants of the present study tended to avoid making changes to the sentence structures of the original text when paraphrasing. Avoidance behaviour is not uncommon in second language acquisition, especially with adult learners (Kleinmann, 1977), and could be considered as a demonstration of learners' language development. However, in the case of paraphrasing, this avoidance strategy might lower the quality of learners' paraphrased texts and deprive them of the opportunity to practice their writing skills while paraphrasing. Understanding this learner preference could therefore be helpful for teachers working with EFL learners who are still relatively new to paraphrasing. That is, while employing a wide range of paraphrasing tasks in writing courses to help these learners practice their paraphrasing skills, teachers should place more emphasis on tasks that specifically require learners to make syntactic transformation, a technique that many of them might avoid.

The participants' failure to understand the text, which then led to their unsuccessful attempt at paraphrasing it, points us to a suggestion that when teaching paraphrasing to less experienced L2 student writers, the teacher should pay close attention to the difficulty level of the source texts that he/she asks students to paraphrase. It might be more effective if the teacher starts with texts that are one or two levels below their students' levels before moving to more advanced ones. This is to ensure that students are able to comprehend the source texts well before learning to paraphrase them, hence helping to build students' confidence to start paraphrasing. Another useful strategy suggested by Wette (2010) to assist with students' comprehension of a source text is to add an "in-between stage" (p. 170) when teaching paraphrasing. This means that instead of paraphrasing directly from a source text, students first work in pairs or groups to orally summarize the text or make a graphic map of it to demonstrate their understanding of the text. They are then asked to paraphrase from these oral summaries or reading maps. Including this transitional phase between reading and paraphrasing gives students the opportunity to unpack the content of the original text before paraphrasing it. Additionally, in this collaborative working process they can recruit help from their peers. Thus, this technique will potentially be helpful for learners who struggle to understand source texts while paraphrasing like some participants of the present study.

With regard to learners' lack of vocabulary for effective paraphrasing, it is suggested that EFL teachers should focus some sessions of their paraphrasing instruction on synonyms. For example, Wette (2010) recommended directing learners' attention to learning a variety of superordinate terms, or nouns that can be used to refer to a class or category of things, to increase their vocabulary size as well as their chance of recalling and using correct synonyms 
when paraphrasing. Additionally, nominalization, the process of removing the human agent by changing a verb or adjective into a noun (Baratta, 2010), could be usefully taught to L2 learners. Nominalization can help to increase learners' vocabulary, especially their knowledge of collocations, and also familiarise them with a commonly used technique to remain objective in academic writing.

\section{Limitations and Conclusion}

The study has some limitations. It was conducted with a small number of participants, which does not allow for generalization of the research findings. In addition, that only one text was employed might not reveal a variety of difficulties that EFL learners might have when encountering various texts of different levels of difficulty. To increase the breadth and depth of the inquiry on EFL learners' paraphrasing skills, future research could recruit a larger number of participants and employ different source texts. Also, given that the current study provides a number of suggestions for L2 teachers to address learners' paraphrasing problems, action research that employs one or more of these strategies could be conducted to explore their effectiveness in paraphrasing instruction.

\section{Author Note}

\section{Chi Do Na, Faculty of Foreign Languages, An Giang University, Vietnam}

Chi Do $\mathrm{Na}$ is a lecturer of English at An Giang University, Vietnam. He teaches Writing and Speaking courses to college students and teachers of English at secondary schools in An Giang province. His research interests are EFL teachers' and students' voices in education, curriculum development, and EFL teacher-student interactions.

\section{Nguyen Xuan Nhat Chi Mai, Hue University, College of Foreign Languages, Vietnam}

Nguyen Xuan Nhat Chi Mai is a lecturer in English at Hue University, College of Foreign Languages, Vietnam. Her research interests are English language teaching methodology, second language teacher education, and teacher professional development.

Contact information: Correspondence concerning this article should be addressed to Chi Do $\mathrm{Na}$, Faculty of Foreign Languages, An Giang University - 118 Ung Van Khiem, Long Xuyen City, An Giang province, Vietnam. E-mail: chidona.ag@gmail.com 


\section{References}

Bailey, S. (2006). Academic writing - A handbook for international students. London, UK: Routledge.

Baratta, A. M. (2010). Nominalization development across an undergraduate academic degree program. Journal of Pragmatics, 42(4), 1017-1036. https://doi.org/10.1016/j.pragma.2009.08.007

Braun, V., \& Clarke, V. (2006). Using thematic analysis in psychology. Qualitative Research in Psychology, 3(2), 77-101. https://doi.org/10.1191/1478088706qp063oa

Chien, S. C. (2014). Cultural constructions of plagiarism in student writing. Research in the Teaching of English, 49(2), 120-140.

http://www.ncte.org/library/NCTEFiles/Resources/Journals/RTE/0492nov2014/RTE0492Cultural.pdf

Coxhead, A. (2000). A new Academic Word List. TESOL Quarterly, 34(2), 213-238. https://doi.org/10.2307/3587951

Dörnyei, Z. (2007). Research methods in applied linguistics: Quantitative, qualitative, and mixed methodologies, Oxford, UK: Oxford University Press.

Gardner, D. (1999). Plagiarism and how to avoid it. Retrieved from The University of Hong Kong http://www4.caes.hku.hk/plagiarism/

Hirvela, A., \& Du, Q. (2013). 'Why am I paraphrasing?': Undergraduate ESL writers' engagement with source-based academic writing and reading. Journal of Eng/ish for Academic Purposes, 12(2), 87-98. https://doi.org/10.1016/j.jeap.2012.11.005

Keck, C. (2006). The use of paraphrase in summary writing: A comparison of L1 and L2 writers. Journal of Second Language Writing, 15(4), 261-278.

https://doi.org/10.1016/j.jslw.2006.09.006

Keck, C. (2014). Copying, paraphrasing, and academic writing development: A reexamination of L1 and L2 summarization practices. Journal of Second Language Writing, 25, 4-22. https://doi.org/10.1016/j.jslw.2014.05.005

Khairunnisa, W., Sutapa, Y., \& Surmiyati, Y. (2014). Students' problems in paraphrasing. Retrieved from http://download.portalgaruda.org/article.php?article=266576\&val=2338\&title=STUDE NTSâ€ $€^{\text {TM }}$ PROBLEMS IN PARAPHRASING

Kleinmann, H. H. (1977). Avoidance behavior in adult second language acquisition. Language Learning, 271), 93-107. https://doi.org/10.1111/j.1467-1770.1977.tb00294.x

Laufer, B., \& Nation, P. (1995). Vocabulary size and use: Lexical richness in L2 written production. Applied Linguistics, 16(3), 307-322. https://doi.org/10.1093/applin/16.3.307

Li, Y., \& Casanave, C. P. (2012). Two first-year students' strategies for writing from sources: Patchwriting or plagiarism? Journal of Second Language Writing, 21(2), 165-180. https://doi.org/10.1016/j.jslw.2012.03.002

Liao, M., \& Tseng, C. (2010). Students' behaviors and views of paraphrasing. Pan-Pacific Association of Applied Linguistics, 14(2), 187-211.

Macbeth, K. P. (2010). Deliberate false provisions: The use and usefulness of models in learning academic writing. Journal of Second Language Writing, 19(1), 33-48. https://doi.org/10.1016/j.jslw.2009.08.002

Milicevic, J., \& Tsedryk, A. (2011). Assessing and improving paraphrasing competence in FSL. Proceedings of the $5^{\text {th }}$ International Conference on Meaning-Text Theory, 176-185. 
Pecorari, D. (2003). Good and original: Plagiarism and patchwriting in academic secondlanguage writing. Journal of Second Language Writing, 12(4), 317-345.

https://doi.org/10.1016/j.jslw.2003.08.004

Phan, L. H. (2006). Plagiarism and overseas students: stereotypes again? ELT Journal, 6011), 76-78. https://doi.org/10.1093/elt/cci085

Richards, J. C., \& Schmidt, R. W. (2010). Longman dictionary of language teaching and applied linguistics. Harlow, UK: Pearson Education.

Rogers, B. (2007). The complete guide to the TOEFL test: Writing. Singapore: Seng Lee Press.

Savier, M. (2004). The Compleat Lexical Tutor, v.4. TESL-EJ, 8(3). Retrieved from http://teslej.org/ej31/m2.html

Shi, L. (2004). Textual borrowing in second-language writing. Written Communication, 21(2), 171-200. https://doi.org/10.1177/0741088303262846

Wette, R. (2010). Evaluating student learning in a university-level EAP unit on writing using sources. Journal of Second Language Writing, 19(3), 158-177.

https://doi.org/10.1016/j.jslw.2010.06.002 


\section{Appendix A}

\section{Original Text for Paraphrasing Practice}

\section{More homework or not more homework!}

Today, kids find that the amount of homework they get keeps them from playing sports, taking music lessons or just having fun after school. A recent study by the University of Michigan reports that over the past 16 years, the amount of time the average 3 to 11 -year-old kid spends on homework has increased by 50 percent. More and more parents are protesting against so much homework.

"The question is whether schools are holding our children captives with homework," said Ken Kiewra, professor of educational psychology. He realized one day last year that his sixthgrade son had given up music lessons, the football team and his favourite hobby because he was loaded down with homework. "I'm home reading the paper and relaxing and this kid who left in the morning before I did is doing two to three hours of work," remembered Kiewra.

In response, Kiewra wrote an article for the Lincoln newspaper. Although parents responded favourably to his article, the school refused to change their homework policies. Kiewra explained that, from the school's point of view, "Research confirms that doing homework is better than not doing homework." He added that pressure for students to perform well on standardized tests has led schools to pile on at-home assignments. All work and no play can make boring kids. "Kids need to play outside and exercise or take art or music classes if they want to," said Ken Kiewra. "At the very least, they need fresh air".

This text is retrieved from perso.menara.ma/mhassim/ReadCompTests.pdf 
Research

\section{Appendix B}

\section{Interview Questions}

1. What do you know about paraphrasing?

2. How did you paraphrase the given text?

3. What were your difficulties in paraphrasing that text? 


\section{Appendix C}

Thematic Analysis Based on Braun \& Clarke (2006): An Example for 'Language-related Difficulties in Paraphrasing' Theme

\begin{tabular}{|c|c|c|}
\hline Phases & Data Analysis Activities & Examples \\
\hline $\begin{array}{l}\text { Locating } \\
\text { relevant data } \\
\text { segments }\end{array}$ & $\begin{array}{l}\text { The whole data set was read } \\
\text { through and segments } \\
\text { containing the participants' } \\
\text { difficulties while paraphrasing } \\
\text { were highlighted. Two of these } \\
\text { segments are provided in the } \\
\text { examples. }\end{array}$ & $\begin{array}{l}\text { Sometimes I couldn't find other } \\
\text { words and_structures to replace the } \\
\text { words in the text so I just reused } \\
\text { them. (Participant 1) } \\
\text { The text is difficult so it is better to } \\
\text { make few and small changes. I was } \\
\text { afraid of changing the meaning of } \\
\text { the text if I changed its syntactic } \\
\text { structures. (Participant 5) }\end{array}$ \\
\hline $\begin{array}{l}\text { Generating } \\
\text { initial codes }\end{array}$ & $\begin{array}{l}\text { All highlighted segments were } \\
\text { read again and initial codes } \\
\text { were generated based on } \\
\text { keywords and phrases in the } \\
\text { segments that directly referred } \\
\text { to difficulties in paraphrasing. } \\
\text { In the examples the codes are } \\
\text { underlined. }\end{array}$ & $\begin{array}{l}\text { Sometimes I couldn't find other } \\
\text { words and structures to replace the } \\
\text { words in the text so I just reused } \\
\text { them. (Participant 1) } \\
\text { The text is difficult so it is better to } \\
\text { make few and small changes. I was } \\
\text { afraid of changing the meaning of } \\
\text { the text if I changed its } \underline{\text { syntactic }} \\
\underline{\text { structures. (Participant 5) }}\end{array}$ \\
\hline $\begin{array}{l}\text { Identifying } \\
\text { themes }\end{array}$ & $\begin{array}{l}\text { Similar codes that could } \\
\text { potentially make a theme were } \\
\text { grouped together. }\end{array}$ & $\begin{array}{l}\text { The above underlined } \\
\text { keywords/phrases demonstrated that } \\
\text { the participants had difficulties with } \\
\text { linguistic aspects of paraphrasing } \\
\text { (e.g., words, sentence structures, } \\
\text { meaning of the text). Based on this a } \\
\text { theme was developed: "Language- } \\
\text { related difficulties in paraphrasing'. }\end{array}$ \\
\hline
\end{tabular}

